\title{
Bias corrections of precipitation measurements across experimental sites in different ecoclimatic regions of western Canada
}

\author{
Xicai Pan ${ }^{1}$, Daqing Yang ${ }^{2}$, Yanping Li ${ }^{1}$, Alan Barr ${ }^{2}$, Warren Helgason ${ }^{1}$, Masaki Hayashi ${ }^{3}$, Philip Marsh ${ }^{4}$, \\ John Pomeroy ${ }^{5}$, and Richard J. Janowicz ${ }^{6}$ \\ ${ }^{1}$ Global Institute for Water Security, University of Saskatchewan, 11 Innovation Boulevard, Saskatoon, Canada \\ ${ }^{2}$ National Hydrology Research Centre, Environment Canada, 11 Innovation Boulevard, Saskatoon, Canada \\ ${ }^{3}$ Department of Geoscience, University of Calgary, Calgary, Alberta, Canada \\ ${ }^{4}$ Cold Regions Research Centre, Wilfrid Laurier University, Waterloo, Ontario, Canada \\ ${ }^{5}$ Centre for Hydrology, University of Saskatchewan, 117 Science Place, Saskatoon, Canada \\ ${ }^{6}$ Water Resources Branch, Yukon Department of Environment, Whitehorse, Yukon, Canada \\ Correspondence to: Yanping Li (yanping.li@usask.ca)
}

Received: 18 May 2016 - Published in The Cryosphere Discuss.: 10 June 2016

Revised: 17 September 2016 - Accepted: 23 September 2016 - Published: 10 October 2016

\begin{abstract}
This study assesses a filtering procedure on accumulating precipitation gauge measurements and quantifies the effects of bias corrections for wind-induced undercatch across four ecoclimatic regions in western Canada, including the permafrost regions of the subarctic, the Western Cordillera, the boreal forest, and the prairies. The bias corrections increased monthly precipitation by up to $163 \%$ at windy sites with short vegetation and sometimes modified the seasonal precipitation regime, whereas the increases were less than $13 \%$ at sites shielded by forest. On a yearly basis, the increase of total precipitation ranged from 8 to $20 \mathrm{~mm}$ (3$4 \%$ ) at sites shielded by vegetation and 60 to $384 \mathrm{~mm}$ (about 15-34\%) at open sites. In addition, the bias corrections altered the seasonal precipitation patterns at some windy sites with high snow percentage ( $>50 \%$ ). This study highlights the need for and importance of precipitation bias corrections at both research sites and operational networks for water balance assessment and the validation of global/regional climate-hydrology models.
\end{abstract}

\section{Introduction}

Accurate precipitation data are essential for understanding climate change and associated hydrological responses from small basins to large regions around the world. However, measuring precipitation, particularly snowfall in cold re- gions, is still difficult. The quality of precipitation measurements is commonly affected by the limitations of the precipitation gauges and by gauge setting and shielding. Precipitation gauge technology has improved significantly in the last century. The most widely used precipitation gauges are classified into four types: manual gauges, tipping bucket rain gauges (TBRGs), weighing type gauges, and optical gauges. Each gauge type has advantages and disadvantages. For instance, the TBRG performs well for liquid precipitation, while the weighing gauge can measure both liquid and solid precipitation in most weather conditions. Depending on site characteristics and environment, gauge performance can vary widely. Results from numerous studies show that gauge type and collection method significantly affect measurement precision and accuracy (Emerson and Macek-Rowland, 1990; Yang et al., 1999). Although all precipitation measurements are prone to bias, the measurement biases are most serious in cold regions due to high snowfall percentage (Goodison et al., 1998; Yang et al., 1998, 1999). Corrections for systematic biases in gauge measurements - such as wind-induced undercatch, wetting loss, evaporation loss, and underestimation of trace precipitation amounts - are necessary (Goodison et al., 1998).

Currently the Geonor T200-B series accumulating gauge is widely used in many nations, including the USA and Canada. Since this type of gauge, through proper implementation and maintenance (i.e. providing sufficient oil or 


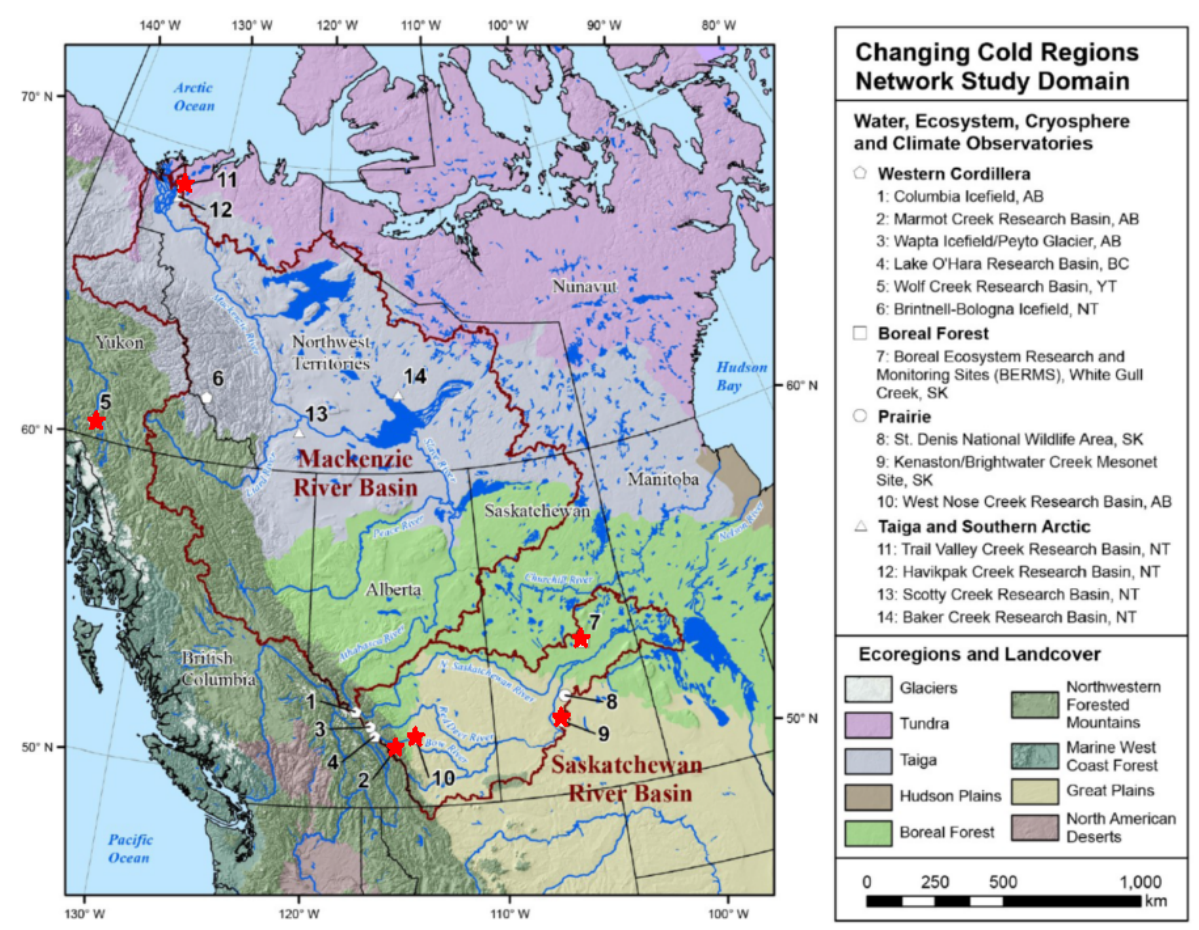

Figure 1. Locations of the selected five study sites (red stars) from the CCRN network with different ecoclimatic regions. Note that the no. 5 includes two data sets. The base map of the interior of western and northern Canada is modified from DeBeer et al. (2016).

antifreeze in the collecting bucket), can prevent excessive evaporation losses, biases due to trace events, wetting loss, and evaporation loss are relatively small in comparison to the wind-induced errors (Goodison et al., 1998; GEONOR, 2012). In addition, a variety of artefacts (noise) associated with high-frequency precipitation data have been observed (Baker et al., 2005; Lamb and Swenson, 2005; Fortin et al., 2008). Properly detecting and excluding noises from the high-time-resolution measurements are essential to quality control and data processing. Automatic precipitation gauges have been used at both network stations and research sites. Relative to national weather stations, the measurement issues are often greater in research networks, where the installations may be in harsh environments and suffer from irregular maintenance. As such, significant effort is required to investigate the quality of precipitation measurements from research sites in the northern regions. Careful analysis of Geonor gauge data collected in different regions will lead to a better understanding of automatic gauge performance and observation biases across various environments.

Corrections for wind-induced gauge undercatch are of great interest for regional climate and hydrology studies. Previous studies (e.g. Yang et al., 1998; Adam and Lettenmaier, 2003) carried out the bias corrections for the national standard (manual) gauges on a daily timescale. This study focused on sub-daily timescale precipitation data measured by automatic precipitation gauges and applies an hourly relationship between wind speed and Geonor gauge catch effi- ciency. Based on a proper data quality control through noise filtering of gauge signals, we quantified the magnitude of the bias corrections at seven selected research sites in western Canada. Specifically, the objectives of this study are (1) to compare the Geonor gauge rainfall data with the TBRG records so as to assess a filtering procedure for different levels of noises; (2) to correct wind-induced undercatch for hourly Geonor gauge measurements; and (3) to compare the magnitude of the bias corrections and to assess their effects on precipitation regimes across different ecoclimatic regions. The methods and results of this study will have a significant impact on regional climate analyses, water balance calculations, and validations of regional climate-hydrology models.

\section{Materials and methods}

\subsection{Sites and data}

Seven research sites were selected from the Changing Cold Regions Network (CCRN) (DeBeer et al., 2016) over the cold interior of western Canada (Fig. 1). These monitoring stations cover four ecoclimatic regions: the permafrost regions of the subarctic, the Western Cordillera, the boreal forest, and the prairies. A brief overview of the sites and data from north to south is given as follows.

The Trail Valley Creek site (TVC) is located $50 \mathrm{~km}$ northnortheast of Inuvik, Northwest Territories, in the continuous permafrost zone. The basin is dominated by gently rolling 
hills and some deeply incised river valleys. The upland tundra area is vegetated with grasses, lichens, and mosses, while shrub tundra occupies the moister hillslopes and valley bottoms with vegetation height ranging from 0.5 to $3 \mathrm{~m}$. The climate is characterized by short summers and long, cold winters with an 8-month snow-cover period. Large snowdrifts form in winter (Pomeroy et al., 1997), and about half of the annual total precipitation (a mean of $231 \mathrm{~mm}$ over 19912000) is in solid form (Marsh et al., 2004).

The Wolf Creek/buckbrush (WCB) and Wolf Creek/forest (WCF) sites are located in the Wolf Creek Research Basin, Yukon Territory, within the upper Yukon River basin. They are representative of the interior subarctic Cordilleran landscape. The typical mountain environment includes dense boreal forest at lower elevations, sparse forest, open meadow and shrub tundra at the higher elevations, and exposed alpine areas with mostly bare rock at the highest elevations. WCB and WCF are situated at two different areas of tall shrub tundra (Pomeroy et al., 2006) and mature white spruce forest (Pomeroy et al., 2002), respectively. The subarctic continental climate is characterized by a large variation in air temperature, low relative humidity, and relatively low precipitation (Wahl et al., 1987). The monthly mean air temperature ranges from $-20^{\circ} \mathrm{C}$ in winter to $15^{\circ} \mathrm{C}$ in summer, and the mean annual precipitation is 300 to $400 \mathrm{~mm}$, with approximately $40 \%$ as snowfall (Janowicz et al., 2004; Rasouli et al., 2014). The used forest gauges were installed in a natural clearing of approximately $15 \mathrm{~m}$ diameter within a dense, mature white spruce forest. The used shrub tundra gauges were installed with their orifice above the shrub canopy.

The old jack pine/Boreal Ecosystem Research and Monitoring Sites (BERMS) site (which originated during the BOReal Ecosystem Atmosphere Study and contributed to FLUXNET Canada) is located in the southern boreal forest within mid-boreal upland and boreal transition ecoregions. The gently rolling landscape is covered by mature jack pine, black spruce, aspen and mixed wood forest, and wetland fen. About one quarter of the annual total precipitation (about $500 \mathrm{~mm}$ ) is received as snow, and the mean annual air temperature is around $0.4{ }^{\circ} \mathrm{C}$ (as observed at Waskesiu Lake over 1971-2000, Barr et al., 2009). The gauges were installed in a natural clearing of approximately $20-30 \mathrm{~m}$ diameter, surrounded by $14 \mathrm{~m}$ tall jack pine trees.

The Brightwater Creek site (BC) is situated in a grazing pasture surrounded by flat agricultural land in the Canadian Prairie region. Solid precipitation commonly occurs between November and April, constituting about one-third of the total annual precipitation $(\sim 400 \mathrm{~mm})$. The average snowpack typically develops to a depth of $15-30 \mathrm{~cm}$, and blowing snow frequently occurs (Pomeroy et al., 1993). The monthly mean air temperature ranges from $-12.9^{\circ} \mathrm{C}$ in January to $18.8^{\circ} \mathrm{C}$ in July.

The West Nose Creek site (WNC) is located at the western edge of the Canadian prairies. The landscape is similar to BC,

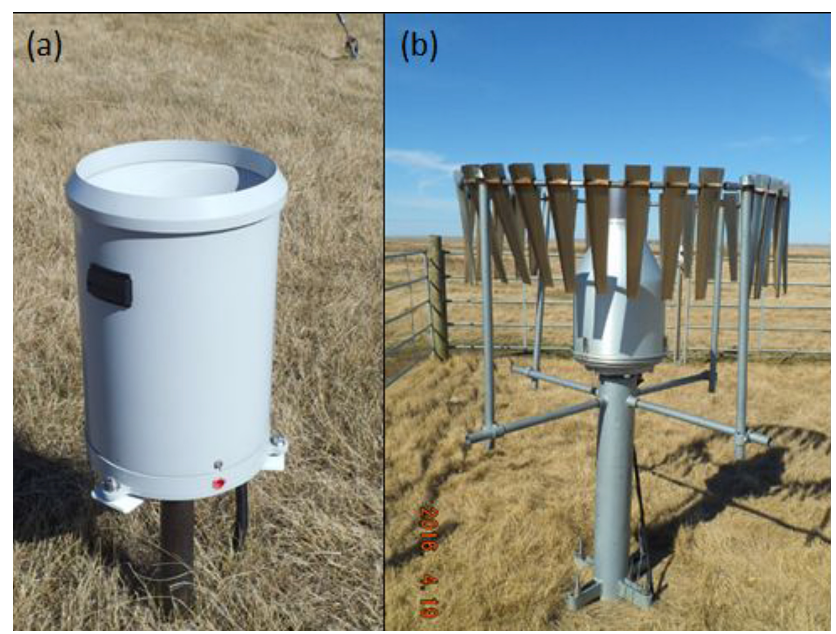

Figure 2. Two types of precipitation gauge used in this study: (a) tipping bucket rain gauge; (b) the single Alter-shielded Geonor T200-B precipitation gauge.

but mid-winter snowmelt often occurs (Mohammed et al., 2013). At the Calgary International Airport, located $20 \mathrm{~km}$ southeast of the site, 1981-2010 normal annual precipitation is $482 \mathrm{~mm}$, and the monthly mean air temperatures in January and July are -7.1 and $16.5^{\circ} \mathrm{C}$, respectively (Hayashi and Farrow, 2014).

The Fisera Ridge/Marmot Creek site (MC) is located in the Rocky Mountain Front Ranges on a larch-covered ridge top at an elevation of $2325 \mathrm{~m}$. The gauge is located on a $3 \mathrm{~m}$ tall pedestal in a $10 \mathrm{~m}$ diameter clearing in the $10 \mathrm{~m}$ tall larch forest. The mountains range in elevation from 1600 to $2800 \mathrm{~m}$, and typical mountain environments include montane and subalpine forest cover, alpine tundra, and talus/rock at higher elevation. The climate is characterized by cool, wet summers and long, cold winters; monthly mean air temperature ranges from $-10.7^{\circ} \mathrm{C}$ in January to $11.7^{\circ} \mathrm{C}$ in July (Pomeroy et al., 2012; Fang et al., 2013; Harder et al., 2015). There is a significant difference in the annual precipitation from $638 \mathrm{~mm}$ at the valley bottom to $1100 \mathrm{~mm}$ at higher elevations (Storr, 1967).

Meteorological variables including air temperature, relative humidity, wind speed, rainfall, and cumulative total precipitation were measured at all sites with an interval of 30 min except the MC site with an interval of $15 \mathrm{~min}$. Sensor information and data periods are listed in Table 1. Two types of precipitation gauges were used at the sites: a TBRG and the Geonor T200-B accumulating gauge, as shown in Fig. 2. The TBRG funnels rain into a mechanical device which tips when it has collected the equivalent of $0.1 \mathrm{~mm}$ of rainfall (amount varies in bucket size). Three types of TBRG were deployed across the seven sites (Table 1): Hydrological Services Tipping Bucket Rain Gauge (Model TB4, Hyquest Solutions PTY LTD); Meteorological Service of Canada tipping bucket; and the TE525MM gauge (Texas Electronics) 
Table 1. Summary of site and instruments info, including heights of the precipitation gauges and wind sensors.

\begin{tabular}{|c|c|c|c|c|c|}
\hline \multirow[t]{2}{*}{ Sites } & \multirow[t]{2}{*}{ Ecoregions } & \multicolumn{3}{|c|}{ Instrument height (m) } & \multirow[t]{2}{*}{ Data period } \\
\hline & & Geonor & TBRG & $\begin{array}{l}\text { Wind } \\
\text { sensor }\end{array}$ & \\
\hline Trail Valley Creek (TVC) & Arctic tundra & $1.82,1.9$ & $1.25^{\mathrm{c}}$ & 1.82 & 2007-2013 \\
\hline Wolf Creek/buckbrush (WCB) & Subarctic shrub tundra & 1.75 & $4.76^{\mathrm{c}}$ & 4.76 & 2011-2012 \\
\hline Wolf Creek/Forest (WCF) & Subarctic forest & 1.75 & $21.34^{\mathrm{c}}$ & 4.8 & 2009-2011 \\
\hline BERMS/old jack pine (BERMS) & Boreal forest & 1.82 & $5.0^{\mathrm{a}}$ & 2.5 & 2014-2015 \\
\hline Brightwater Creek/Kenaston (BC) & Prairie/pasture & 1.5 & $0.3^{\mathrm{a}}$ & 2.0 & 2009-2015 \\
\hline West Nose Creek/Woolliams Farm (WNC) & Prairie/cropland & 1.5 & $0.4^{\mathrm{b}}$ & 1.55 & 2006-2013 \\
\hline Marmot Creek/Fisera Ridge (MC) & Western Cordillera/alpine tundra & $3.1 / 4.1^{*}$ & $4.2^{\mathrm{a}}$ & $3.2 / 4.2^{*}$ & 2011-2015 \\
\hline
\end{tabular}

${ }^{a}$ Hydrological Services Tipping Bucket Rain Gauge (TB4). ${ }^{\mathrm{b}}$ Meteorological Service of Canada tipping bucket. ${ }^{\mathrm{c}}$ TE525MM gauge (Texas Electronics). * Since 8 February 2013

were used at these sites. The Geonor T200-B gauge was deployed in a standard configuration with a (single) Alter shield (which we will denote Geonor-SA) to increase the snowfall catch efficiency (Fig. 2b). The measuring mechanism of the Geonor T200-B uses one or more vibrating wires to continuously weigh the content in the bucket. It can record changes with a resolution of $0.1 \mathrm{~mm}$ at timescale up to minutes. To prevent freezing, an antifreeze blend (methanolethylene/propylene glycol, e.g. $60: 40$ ) was added to the solution in the bucket to melt frozen precipitation. Regular hydraulic oil (recommended amount $0.4 \mathrm{~L}$ ) was added to the Geonor gauge container to minimize losses by evaporation.

\subsection{Algorithms for data processing}

The output from the Geonor accumulating gauge was postprocessed: to identify individual precipitation events and to correct for long-term drift associated with sublimation and evaporation. Diurnal (or a bit longer) noise often occurs at sites with strong diurnal changes in temperature, radiation, and wind speed. Long-term drift results from evaporation from inside the bucket (Duchon, 2008). A general algorithm for data processing was applied in two steps: (1) manual prefiltering to remove obvious outliers and eliminate changes associated with gauge servicing, e.g. emptying and/or adding of antifreeze and oil, and (2) automated filtering to eliminate the above-mentioned two types of noises. Step 2 used a "brute-force" filtering algorithm to eliminate negative and small positive changes by combining them with proximate, positive changes above a specified threshold, here set to $0.1 \mathrm{~mm}$, the precision of the Geonor T200-B gauge. The brute-force filter preserves the total precipitation accumulation but aggregates all changes into values above the threshold. The brute-force filtering algorithm involved three steps. Step 2.1 computed the 30 min precipitation amount, which we will denote as $P$, as the difference between consecutive values in the cumulative precipitation time series. Step 2.2 flagged all $P$ values below the specified $(0.1 \mathrm{~mm})$ threshold and sorted them from lowest to highest. Step 2.3 eliminated the flagged $P$ values from 2.2 by combining them with the nearest positive values and then setting them to zero. One by one, beginning with the lowest, each flagged $P$ value was added to the nearest positive $P$ value and then set to zero. The nearest positive value could occur either earlier or later in the time series; when two nearest positive values were equidistant before and after the flagged value, the flagged $P$ value was added to the larger of the positive values. After the lowest flagged value had been processed and set to zero, the remaining $P$ values were sorted in ascending order, and the lowest remaining value was processed next. Step 2.3 was repeated until all $P$ values below the specified threshold had been eliminated.

The brute-force filter from this study assumes that the cumulative precipitation total is correct and will thus fail during periods with visually evident declines in the time series. When negative drift was observed, its impact was minimized by applying the filter over a moving window of one or a few days. The window size is related to the drift period. All filtering was visually supervised to confirm that it performed reasonably.

\subsection{Correcting for Geonor-SA undercatch}

After filtering, $30 \mathrm{~min}$ precipitation data were produced for all the sites with different observational time periods. With these data, a bias correction was applied to solid precipitation, using an empirical relationship between catch efficiency and wind speed derived in Canada (Smith, 2007):

$P_{\text {corr }}=P_{\text {obs }} / \mathrm{CE}, \quad \mathrm{CE}=1.18 e^{-0.18 W_{\mathrm{s}}}$,

where $P_{\text {corr }}(\mathrm{mm})$ is the corrected precipitation, $P_{\text {obs }}(\mathrm{mm})$ is the measured solid precipitation after filtering, catch efficiency $\mathrm{CE}$ is the ratio of the Geonor catch to the "true" snowfall measured by a WMO reference called the double fence intercomparison reference (DFIR) (Goodison et al., 1998), and $W_{\mathrm{s}}\left(\mathrm{m} \mathrm{s}^{-1}\right)$ is the hourly mean wind speed at the gauge height. Wind-induced bias corrections are also necessary for rainfall, though they are not as significant as for 
Table 2. Additional formulas for Eq. (2).

\begin{tabular}{lll}
\hline 1. Diffusivity of water vapour in air, $D\left[\mathrm{~m}^{2} \mathrm{~s}^{-1}\right]$ & $D=2.06 \times 10^{-5} \times\left(\frac{T_{\mathrm{a}}+273.15}{273.15}\right)^{1.75}$ & Thorpe and Mason (1966) \\
\hline 2. Thermal conductivity of air, $\lambda_{\mathrm{t}}\left[\mathrm{J} \mathrm{m}^{-1} \mathrm{~s}^{-1} \mathrm{~K}^{-1}\right]$ & $\lambda_{\mathrm{t}}=0.000063 \times\left(T_{\mathrm{a}}+273.15\right)+0.00673$ & List (1949) \\
\hline 3. Sublimation and vaporization, $L\left[\mathrm{~J} \mathrm{~kg}^{-1}\right]$ & $L=\left\{\begin{array}{cc}1000 \times\left(2834.1-0.29 T-0.004 T^{2}\right), \quad T<0 \\
1000 \times(2501-2.36 T),\end{array}\right.$ & $T \geq 0$ \\
\hline 4. Water vapour density, $\rho\left[\mathrm{kg} \mathrm{m}^{-3}\right]$ & $\rho=\frac{m_{\mathrm{W}} e}{R T}$, \\
& $\begin{array}{l}m_{\mathrm{W}}: \text { the molecular weight of water, } 0.01801528\left[\mathrm{~kg} \mathrm{~mol}^{-1}\right] ; \\
\text { Rogers and Yau (1989) }\end{array}$ \\
\hline Vapour pressure, $e[\mathrm{kPa}]$ & $e=\frac{\mathrm{RH}}{100} \times 0.611 e^{\frac{17.3 T}{237.3+T}}$ & \\
\hline
\end{tabular}

snowfall (Goodison et al., 1998; Yang, 1998). An investigation of rainfall measurements at Egbert, Ontario (Devine and Mekis, 2008), showed a catch ratio of $95 \%$ for the GeonorSA relative to a pit gauge, the WMO reference for rainfall intercomparison (WMO, 1969). Thus, we adjusted all rainfall measurements using the average catch efficiency of $95 \%$ $(\mathrm{CE}=0.95)$.

Over-correction is possible for snowfall events due to the impact of blowing snow at high wind speeds. To avoid overcorrection, an upper threshold wind speed is required (Goodison et al., 1998). For daily precipitation totals, an upper threshold for daily mean wind speed of $6.5 \mathrm{~m} \mathrm{~s}^{-1}$ is often applied in Arctic and northern regions (Yang et al., 2005). In this study, we used lower and upper threshold $W_{\mathrm{s}}$ of 1.2 and $9.0 \mathrm{~m} \mathrm{~s}^{-1}$, respectively. Thus, CE was set to 1.0 when $W_{\mathrm{s}}<1.2 \mathrm{~m} \mathrm{~s}^{-1}$ and to 0.23 (CE for $9 \mathrm{~m} \mathrm{~s}^{-1}$ wind speed) when $W_{\mathrm{s}}>9.0 \mathrm{~m} \mathrm{~s}^{-1}$. Smith (2007) tested this relationship at an open and windy site near Regina and concluded the method was generally applicable for the interior of western Canada or other regions.

The bias correction algorithm for precipitation measurements requires the determination of precipitation types. A variety of approaches for precipitation phase determination has been summarized in Harder and Pomeroy (2013). Commonly, a double temperature threshold is used to distinguish snowfall, rainfall, and mixed events. All precipitation below the lower threshold or above the upper threshold is considered as snow or rain, respectively, and between the defined thresholds is then considered to be mixed with a certain proportion (Pipes and Quick, 1977). With a solid physical basis, a threshold of hydrometeor temperature $\left(T_{\mathrm{i}}\right)$, approximating the temperature at the surface of a falling hydrometeor is more robust than others directly using air temperature $\left(T_{\mathrm{a}}\right)$ or dew point temperature $\left(T_{\mathrm{d}}\right)$ (Harder and Pomeroy, 2013). The $T_{\mathrm{i}}$ can be derived from near-surface meteorological variables including air temperature and humidity by using the psychrometric energy balance method (Harder and Pomeroy, 2013):

$T_{\mathrm{i}}=T_{\mathrm{a}}+\frac{D}{\lambda_{\mathrm{t}}} L\left(\rho_{T_{\mathrm{a}}}-\rho_{\mathrm{sat}\left(T_{\mathrm{i}}\right)}\right)$.
Corresponding parameters for Eq. (2) are listed in Table 2. An empirical relationship between $T_{\mathrm{i}}$ and the rainfall fraction $f_{\mathrm{r}}$ is then applied to separate snowfall and rainfall in precipitation measurements:

$f_{\mathrm{r}}\left(T_{\mathrm{i}}\right)=\frac{1}{1+b \times c^{T_{\mathrm{i}}}}$,

where the calibrated coefficients $b=2.630006$ and $c=0.09336$ are based on the measurements $(15 \mathrm{~min}$ time interval) in a small Canadian Rockies catchment, Marmot Creek Research Basin (Harder and Pomeroy, 2013).

Wind speed at gauge height is necessary to determine gauge undercatch. When wind speed was not measured at gauge height, it was estimated from wind field profile models over different canopies. For open site with short grass (e.g. BC and WNC), a logarithmic model is employed as

$W_{\mathrm{s}}(h)=W_{\mathrm{s}}(H)\left[\frac{\ln \left(h / z_{0}\right)}{\ln \left(H / z_{0}\right)}\right]$,

where $W_{\mathrm{s}}(h)$ is the estimated hourly mean wind speed at the gauge height $\left(\mathrm{m} \mathrm{s}^{-1}\right), W_{\mathrm{s}}(H)$ is the measured hourly mean wind speed at the available height $\left(\mathrm{m} \mathrm{s}^{-1}\right), H$ is the height of the available anemometer $(\mathrm{m})$, and $z_{0}$ is the roughness length $(\mathrm{m})$ set to $0.01 \mathrm{~m}$ for the cold period for snow surface $\left(T_{\mathrm{a}} \leq 0^{\circ} \mathrm{C}\right)$ and $0.03 \mathrm{~m}$ for short grass in the warm period $\left(T_{\mathrm{a}}>0{ }^{\circ} \mathrm{C}\right)$ (Yang et al., 1998). For sites with shrub or forest canopies (e.g. WCB and WCF), wind speed within canopy is calculated from an exponential wind profile model (Cionco, 1965):

$W_{\mathrm{s}}(h)=W_{\mathrm{s}}(H) \exp \left(\alpha\left(h / h_{0}-1\right)\right)$,

where $h_{0}$ is the average canopy height $(\mathrm{m}), W_{\mathrm{s}}(H)$ is the mean wind speed at the canopy height, and $\alpha$ is the canopy flow index. The wind speed measurements above canopy at WCB and WCF are approximately assumed at the canopy height, and $\alpha$ is set as 1.7 for shrub and forest based on suggested values for similar canopies (e.g. Raupach et al., 1996; Wang and Cionco, 2007). In addition, the wind speed measurements at BERMS are assumed as at gauge height due to the small height difference. 


\section{Results}

\subsection{Geonor-SA vs. TBRG for rain}

Except the tiny noise caused by the high-frequency electromagnetic disturbances from natural resources, the major measurement noise in this study can be grouped into two classes: (1) irregular diurnal or longer drift, depending on the timescale of temperature or wind speed fluctuations, and (2) evident declines in the accumulation due to evaporation losses. Examples of the two typical types of noise in Geonor precipitation measurements and corresponding filtering are shown in Fig. 3. The former occurs at all sites, with a dynamic range of $\pm 0.1 \mathrm{~mm}$ at the forest sites, e.g. BERMS, to $\pm 3 \mathrm{~mm}$ at the grassland sites, e.g. BC. This type of noise is usually larger in cold periods than in warm seasons and can be related to turbulent pressure fluctuations (i.e. wind pumping), as well as diurnal temperature effects on gauge transducers. The second type of noise, evaporation losses, occurred at most sites. However, significant declines are mainly observed at MC due to the exceptional circumstances postflood with no oil added in the gauge.

Relative to TBRG observations, the filtering of Geonor observations may produce artefacts, erroneously creating or removing light rainfall events. The effect of filtering on Geonor precipitation measurements can be assessed by comparing the filtered rainfall from the Geonor-SA $\left(P_{\mathrm{g}}\right)$ with the TBRG measurements $\left(P_{\mathrm{t}}\right)$ (Fig. 4). Overall, the rainfall measurements by the two gauges (the blue dots around the $1: 1$ line) agree closely at all sites. A few notable differences like in Fig. 4k are attributed to poor performance of the TBRG at WNC during some heavy events, where over-measurement can be deduced by comparison with the Geonor measurements. In addition, the relatively small differences might be attributed to different catch efficiencies.

Two special cases for "missing" measurements, with (1) $P_{\mathrm{t}}>0$ and $P_{\mathrm{g}}=0$ and (2) $P_{\mathrm{t}}=0$ and $P_{\mathrm{g}}>0$, are marked with red and black circles in the left panels of Fig. 4. Generally, most missing measurements of heavy rainfall (e.g. $>5 \mathrm{~mm} 30 \mathrm{~min}^{-1}$ ) are related to a false record in both gauges; however their occurrence is rare. In contrast, missing measurements of light rainfall occur frequently, related to the artefacts of filtering. In situations of widely fluctuating noise, since brute-force filter may introduce anomalous rainfall events or remove real events (e.g. Fig. 3a), without adding bias to the total accumulation, the annual totals of missing $P_{\mathrm{t}}$ in case (1) and missing $P_{\mathrm{g}}$ in case (2) should be approximately equal.

Yearly totals of missing $P_{\mathrm{t}}$ and $P_{\mathrm{g}}$ are shown in the right panel in Fig. 4. For example, BC (Fig. 4j) has yearly totals of missing $P_{\mathrm{t}}$ from 12 to $48 \mathrm{~mm}$ and $P_{\mathrm{g}}$ from 16 to $46 \mathrm{~mm}$. The absolute offsets are all less than $7 \mathrm{~mm}$ except in 2010 . Through comparing the missing measurements of $P_{\mathrm{t}}$ and $P_{\mathrm{g}}$, we have found most events are light precipitation $(<1 \mathrm{~mm})$ and are introduced by the $P_{\mathrm{g}}$ filtering. Light precipitation
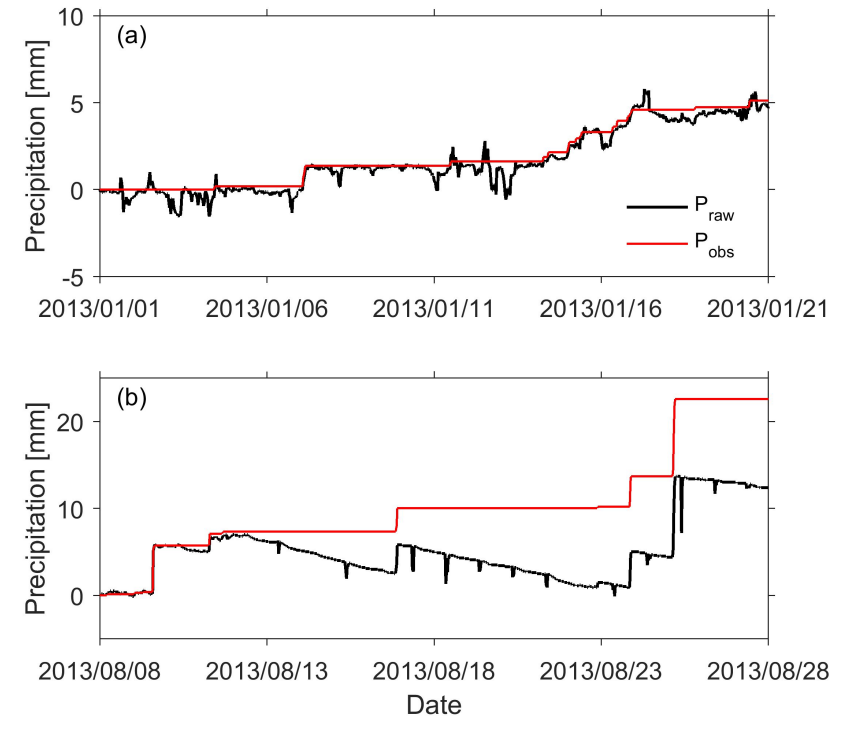

Figure 3. Examples of typical noise filtering for Geonor precipitation measurements ( $P_{\text {raw }}$ : raw data; $P_{\text {obs }}$ : filtered data). (a) Diurnal drift, e.g. BC. (b) Evaporation-caused drops, e.g. MC.

events can be masked by diurnal fluctuations of noise, which can be removed by the filter. On the other hand, the filter may anomalously create light precipitation events near the start of actual rain events. For yearly totals, the two artefacts of created and removed rainfall events offset each other and do not introduce significant bias. In contrast, the notable imbalance between $P_{\mathrm{t}}$ and $P_{\mathrm{g}}$ in 2010 is related to the obvious missing measurements of $P_{\mathrm{t}}$, which are likely caused by false TBRG readings, related to TBRG plugging. Similar results can be found at TVC. But the yearly totals of missing $P_{\mathrm{t}}$ and $P_{\mathrm{g}}$ except 2013 are smaller $\left(<15 \mathrm{~mm} \mathrm{yr}^{-1}\right)$ because of lower noise and fewer rainfall events at TVC than BC. The site WNC has particularly large imbalances between $P_{\mathrm{t}}$ and $P_{\mathrm{g}}$, which is due to false Geonor and TBRG readings. In addition, hailstorms in this region may also contribute to the imbalances.

Overall, we conclude that the filtering algorithm works well at the study sites, although it sometimes removes and creates some light precipitation events - case (1) and case (2). The number of these two artefacts is influenced by noise status and precipitation characteristics. However, the two artefacts typically offset each other so that the net effect is usually small $\left(<20 \mathrm{~mm} \mathrm{yr}^{-1}\right)$ for rainfall data.

\subsection{Monthly precipitation and bias corrections}

Based on $30 \mathrm{~min}$ data and bias corrections, Fig. 5 summarizes the bias correction for wind-induced undercatch at monthly timescales. The left panels compare the monthly mean values of measured and corrected precipitation over the period 2006-2015; the corresponding meteorological summaries are shown in the right panels. Generally, the effects of the bias corrections on precipitation measurements at the 

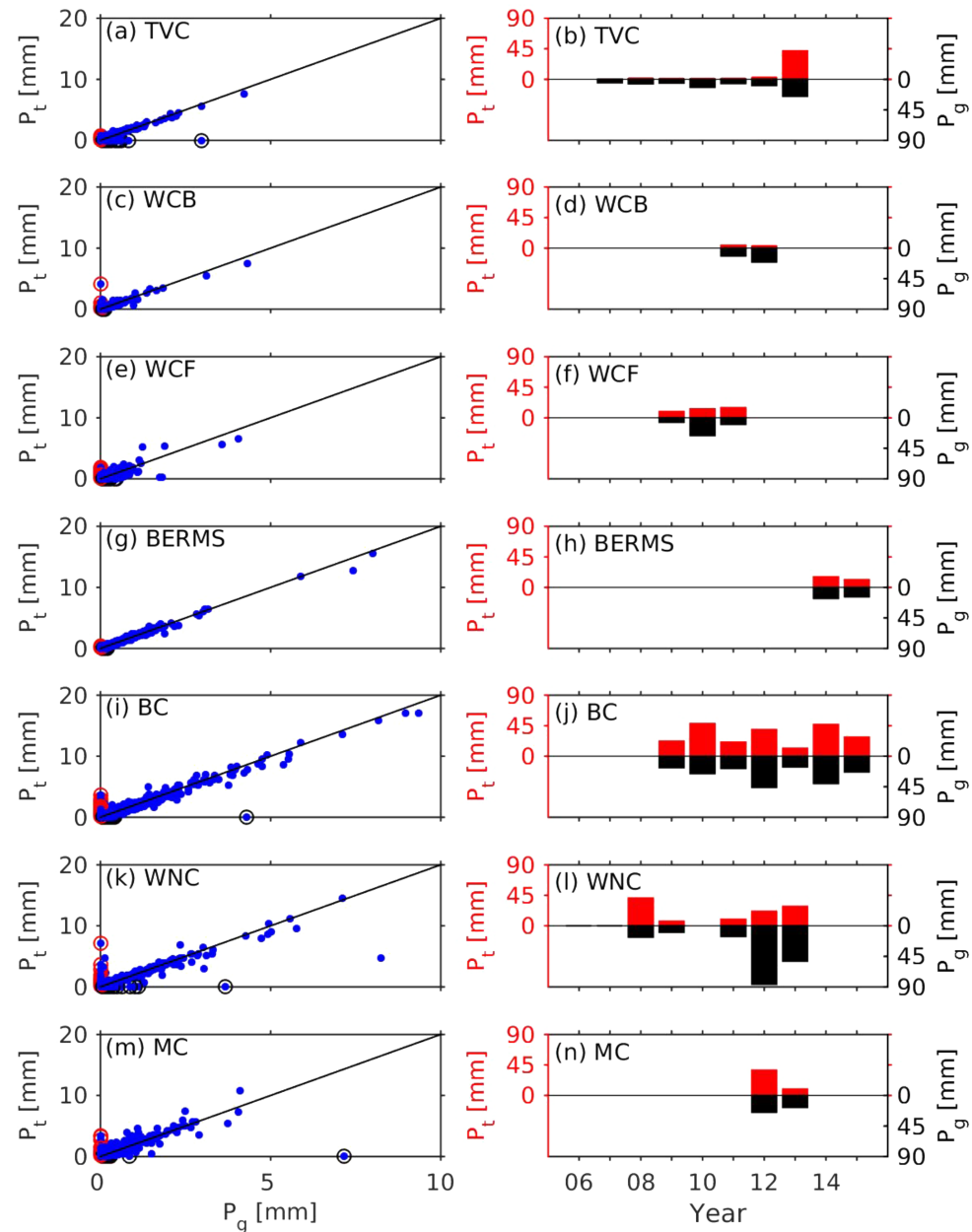

Figure 4. Comparison of rainfall rates from TBRG $\left(P_{\mathrm{t}}\right)$ and Geonor-SA $\left(P_{\mathrm{g}}\right)$ measurements at the sites $(\mathrm{TVB}, \mathrm{WCB}, \mathrm{WCF}, \mathrm{BERMS}, \mathrm{BC}$, WNC, and MC). The left panel compares the rainfall rates at timescales of $30 \mathrm{~min}$ over the whole period. Cases where only one of the gauges did measure precipitation are extra marked: red circles for $P_{\mathrm{t}}>0$ and $P_{\mathrm{g}}=0$, and black circles for $P_{\mathrm{t}}=0$ and $P_{\mathrm{g}}>0$. The right panel shows the yearly total amounts of "missing" precipitation at the two gauges.

study sites are controlled by their ecoclimatic characteristics. Here the results are described from north to south across the study region.

For TVC, the results show monthly measured precipitation ranging from 5 to $35 \mathrm{~mm}$, with the minimum in April and the maximum in August. Monthly corrections for windinduced undercatch vary from 2 to $11 \mathrm{~mm}$, or about 5-163\% increase of the gauge-measured amounts. The relative increase of monthly precipitation is much higher in the cold season (October to May) than in the warm season (June to September), due to the higher wind-induced undercatch for snow than for rain and the smaller amount of absolute precipitation in the cold season. It is interesting to note the changes, due to bias corrections, in the precipitation regime at this site. Winter precipitation is doubled after the corrections because of strong winds and very low temperatures. The annual precipitation cycle continues to peak in summer, but signif- icant bias corrections in winter reduce the winter-summer contrast.

At WCB, the monthly measured precipitation ranges from 12 to $55 \mathrm{~mm}$, with the minimum in April and the maximum in August. Monthly corrections for wind-induced undercatch vary from 0 to $3 \mathrm{~mm}$, or about $0-5 \%$ of the gauge-measured amounts. The monthly mean wind speeds are always below the lower threshold $\left(1.2 \mathrm{~m} \mathrm{~s}^{-1}\right)$. The corrections for snowfall undercatch are negligible in the cold season (November to May) due to the low wind speed. The corrections for rain undercatch are relatively higher in the warm season (May to October) due to a constant correction factor of $5 \%$. As a result, over-correction might occur for rainfall.

Monthly measured precipitation at WCF ranges from 2 to $55 \mathrm{~mm}$, with the minimum in March and the maximum in August. Monthly corrections for wind-induced undercatch vary from 0 to $3 \mathrm{~mm}$, or about $0-5 \%$ increase of the gaugemeasured amounts. The monthly mean wind speeds are al- 


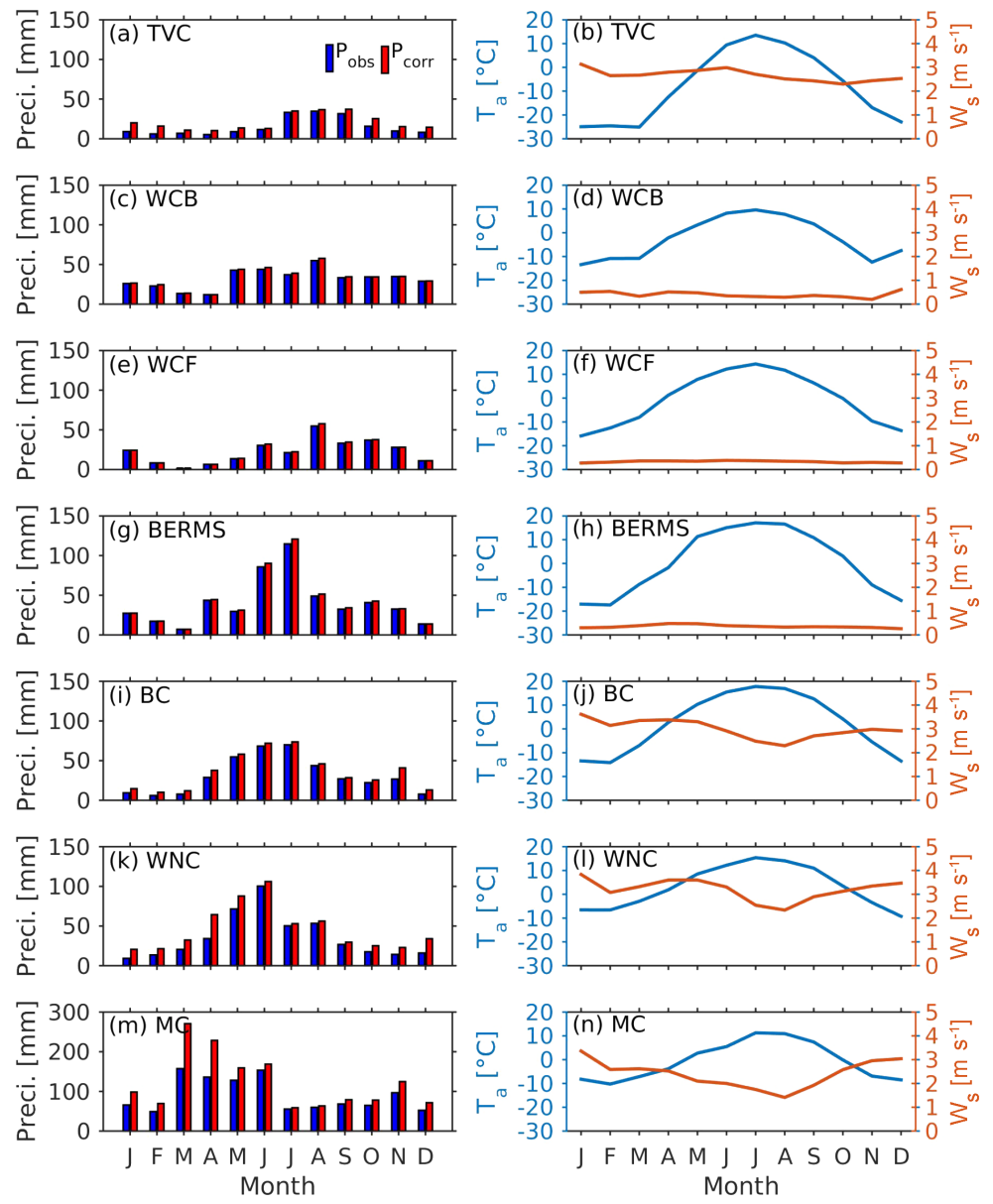

Figure 5. Comparison of precipitation correction in six different ecoclimatic regions. The left column plots (a, c, e, g, i, k, and $\mathbf{m})$ compare the monthly averaged uncorrected and corrected precipitation rates $\left(P_{\mathrm{obs}}\right.$ and $\left.P_{\mathrm{corr}}\right)$ at sites TVB, WCB, WCF, BERMS, BC, WNC, and MC, respectively; the right column plots $(\mathbf{b}, \mathbf{d}, \mathbf{f}, \mathbf{h}, \mathbf{j}, \mathbf{l}$, and $\mathbf{n})$ show the monthly mean air temperature $\left(T_{\mathrm{a}}\right)$ and gauge-height wind speed $\left(W_{\mathrm{S}}\right)$ at corresponding sites. Note the doubled scale of the $y$ axis in metres $(\mathrm{m})$.

ways below the lower threshold $\left(1.2 \mathrm{~m} \mathrm{~s}^{-1}\right)$. Similar to WCB, the negligible corrections for snowfall undercatch are due to the low wind speeds $\left(1.2 \mathrm{~m} \mathrm{~s}^{-1}\right)$.

The results for BERMS show monthly measured precipitation from 7 to $115 \mathrm{~mm}$, with the minimum in March and the maximum in July. Monthly corrections for wind-induced undercatch vary from 0 to $6 \mathrm{~mm}$, or about $0-5 \%$ increase of the gauge-measured amounts. The monthly mean wind speeds are always below the lower threshold $\left(1.2 \mathrm{~m} \mathrm{~s}^{-1}\right)$. The corrections for snowfall undercatch are negligible in the cold season (November to April).

Monthly measured precipitation at $\mathrm{BC}$ ranges from 6 to $70 \mathrm{~mm}$, with the minimum in February and the maximum in July. Monthly corrections for wind-induced undercatch vary from 1 to $14 \mathrm{~mm}$, or about $5-70 \%$ increase of the gaugemeasured amounts. The relative increase of monthly precipitation is much higher (4-14 mm and 16-70\%) in the cold season (October to April) than in the warm season (1-4 mm and 5-6\%) (May to September), mainly due to the higher wind-induced undercatch for snow than for rain and also due to the smaller amount of absolute precipitation in the cold season.

Monthly measured precipitation at WNC ranges from 9 to $100 \mathrm{~mm}$, with the minimum in January and the maximum in June. Monthly corrections for wind-induced undercatch vary from 3 to $30 \mathrm{~mm}$, or about $5-123 \%$ increase of the gaugemeasured amounts. The relative increase of monthly precipitation is much higher (23-123\%) in the cold season (October to May) than 5-23\% in the warm season (June to September), mainly due to the higher wind-induced undercatch for snow than for rain. It is interesting to notice the changes, due to bias corrections, in precipitation regime at this site. Winter month precipitation has been doubled after the corrections because of high winds and very low temperatures.

For MC, monthly measured precipitation varies from 49 to $157 \mathrm{~mm}$, with the minimum in February and the maximum in March. Monthly corrections for wind-induced undercatch ranges from 3 to $113 \mathrm{~mm}$, or about $6-72 \%$ increase of the 

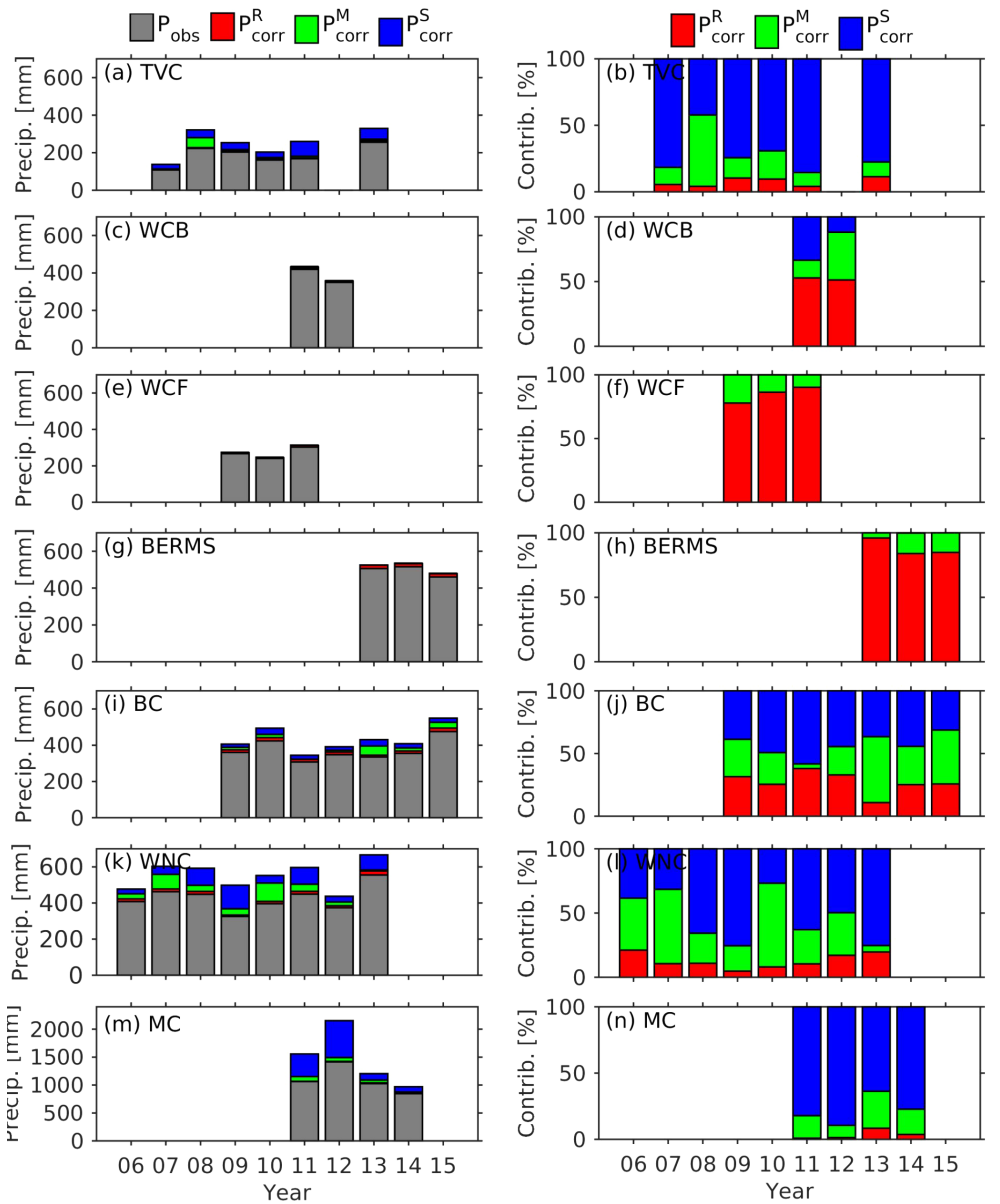

Figure 6. Variation of annual precipitation correction at the same sites as Fig. 5. The left column plots (a, c, e, g, i, k, and m) demonstrate the components of annual total precipitation: observed precipitation, corrected rain, corrected mixed precipitation, and corrected snow $\left(P_{\text {obs }}\right.$, $\left.P_{\text {corr }}^{\mathrm{R}}, P_{\text {corr }}^{\mathrm{M}}, P_{\mathrm{corr}}^{\mathrm{S}}\right)$ over the period of 2006-2015. The right column plots $(\mathbf{b}, \mathbf{d}, \mathbf{f}, \mathbf{h}, \mathbf{j}, \mathbf{l}$, and $\mathbf{n})$ show the annual contributions of the three precipitation types in percentage of the corrected precipitation amount.

gauge-measured amounts. The relative increase of monthly precipitation is much higher in the cold season (October to May) than in the warm season (June to September), as the result of higher wind induced undercatch for snow than for rain. Particularly, monthly corrections in March and April reach 113 and $93 \mathrm{~mm}$, respectively. Bias corrections significantly modify precipitation regime especially in March and June.

In comparison, wind corrections for snowfall undercatch at the above sites can be grouped into two classes. For the sites WCB, WCF, and BERMS with shielding of surrounding forest or brush, the corrections are negligible due to lowf wind speeds. For the open sites TVC, BC, WNC, and MC, the corrections are high and vary among the sites, depending on regional climate factors such as air temperature, wind speed, and snowfall percentage. For BC and WNC in the Prairie region, the rainfall-dominated precipitation regime remains the same after the bias corrections. Significant changes in precipitation regimes occur at TVC in the Arctic region due to the higher monthly mean correction factor $(97 \%)$ than that of $70 \%$ in the cold season at the Prairie sites. The most significant change in precipitation regime appears at MC in the Rocky Mountain Front Range due to the high snow percentage and high wind speed.

\subsection{Annual precipitation and bias correction}

An annual overview of the bias corrections is shown in Fig. 6, stratified by measured total precipitation, corrected rain, corrected mixed precipitation, and corrected snow $\left(P_{\mathrm{obs}}, P_{\mathrm{corr}}^{\mathrm{R}}\right.$, $\left.P_{\text {obs }}^{\mathrm{M}}, P_{\text {corr }}^{\mathrm{S}}\right)$. The annual totals are shown in the left panels, and the corresponding contributions of the three precipitation types in the annual corrected totals are shown in the right panels.

For TVC, yearly measured precipitation ranges from 108 to $256 \mathrm{~mm}$ with a mean of $187 \mathrm{~mm}$. Yearly corrected precipitation varies from 138 to $329 \mathrm{~mm}$ with a mean of $251 \mathrm{~mm}$. The mean increase is $64 \mathrm{~mm}$, or $34.3 \%$. The annual mean 
contributions of bias corrections for rainfall, mixed precipitation, and snowfall are $7.5,20.8$, and $71.7 \%$, respectively. The bias corrections affect the interannual precipitation variability. For example, the ranking of 2011 precipitation changed from the fourth to the third.

For WCB, yearly measured precipitation ranges from 350 to $419 \mathrm{~mm}$ with a mean of $385 \mathrm{~mm}$. Yearly corrected precipitation varies from 359 to $435 \mathrm{~mm}$ with a mean of $397 \mathrm{~mm}$. The mean increase is $12 \mathrm{~mm}$, or about $3.1 \%$. The annual mean contributions of bias corrections for rainfall, mixed precipitation, and snowfall are 52.0, 25.3, and $22.7 \%$, respectively. The bias corrections do not change much of the precipitation pattern due to the high catch efficiency at this shielded site.

For WCF, yearly measured precipitation ranges from 241 to $303 \mathrm{~mm}$ with a mean of $270 \mathrm{~mm}$. Yearly corrected precipitation varies from 247 to $314 \mathrm{~mm}$ with a mean of $279 \mathrm{~mm}$ for 2009-2011. The mean increase is $8 \mathrm{~mm}$, or $3.0 \%$. The annual mean contributions of bias corrections for rainfall, mixed precipitation, and snowfall are 84.8, 15.2, and $0.0 \%$, respectively. Yearly precipitation pattern remains the same after the corrections.

For BERMS, yearly measured precipitation ranges from 461 to $516 \mathrm{~mm}$ with a mean of $494 \mathrm{~mm}$. Yearly corrected precipitation varies from 480 to $535 \mathrm{~mm}$ with a mean of 514 $\mathrm{mm}$. The mean increase is $20 \mathrm{~mm}$, or $4 \%$. The annual mean contributions of bias corrections for rainfall, mixed precipitation, and snowfall are 88.2, 11.7, and $0.1 \%$, respectively. There is not much change in the interannual precipitation variation due to the high catch efficiency at this forest site.

Yearly measured precipitation at BC ranges from 308 to $475 \mathrm{~mm}$ with a mean of $372 \mathrm{~mm}$. The snow percentage ranges from 11.0 to $39.0 \%$. Yearly corrected precipitation varies from 345 to $549 \mathrm{~mm}$ with a mean of $432 \mathrm{~mm}$. The mean increase is $60 \mathrm{~mm}$, or $15.1 \%$. The annual mean contributions of bias corrections for rainfall, mixed precipitation, and snowfall are $27.1,29.6$, and $43.3 \%$, respectively. There is little change in the ranking of yearly precipitation due to the relative uniform and the low correction factor.

For WNC, yearly measured precipitation ranges from 325 to $555 \mathrm{~mm}$ with a mean of $427 \mathrm{~mm}$. Yearly corrected precipitation varies from 437 to $667 \mathrm{~mm}$ with a mean of $553 \mathrm{~mm}$. The mean increase is $126 \mathrm{~mm}$, or $30.2 \%$. The annual mean contributions of bias corrections for rainfall, mixed precipitation, and snowfall are $12.9,33.9$, and $53.2 \%$, respectively. The ranking of yearly precipitation has changed, and the observed minimum precipitation in 2009 became the sixth in yearly corrected precipitation.

At MC, yearly measured precipitation ranges from 847 to $1414 \mathrm{~mm}$ with a mean of $1087 \mathrm{~mm}$. The snow percentage ranges from 57.3 to $76.1 \%$. Yearly corrected precipitation varies from 970 to $2153 \mathrm{~mm}$ with a mean of $1471 \mathrm{~mm}$. The mean increase is about $384 \mathrm{~mm}$, or $32.6 \%$. The annual mean contributions of bias corrections for rainfall, mixed precipitation, and snowfall are 3.6, 18.3, and $78.1 \%$, respectively.
The ranking of yearly precipitation does not change much, but the increase in 2012 reached $739 \mathrm{~mm}$ due to heavy snowfall in spring.

In summary, the impact of the bias corrections on yearly precipitation is small at the sheltered sites with vegetation shielding (WCB, WCF, and BERMS), ranging from 8 to $20 \mathrm{~mm}$, or 3-4\%. At these sites, the bias corrections do not change the precipitation patterns during the study periods. In contrast, the change in annual precipitation is larger at the open sites (TVC, BC, WNC, and MC), ranging from 60 to $384 \mathrm{~mm}$, or $15-34 \%$. In addition, the bias corrections significantly alter the seasonal patterns of precipitation at windy sites with high snow percentage ( $>50 \%$ ) (TVC and WNC). Similar features of precipitation bias corrections have been reported over the high-latitude regions (Yang and Ohata, 2001; Adam and Lettenmaier, 2003; Yang et al., 2005).

\section{Discussion}

Uncertainties exist in the analysis and intercomparison of precipitation gauge data and bias corrections. These include, for example, precipitation type determination including blowing snow events, observations, and calculations of mean wind speed and temperature for the time period of precipitation (Yang and Simonenko, 2014). Here we discuss some of the issues relevant to this study.

\subsection{Light rain and snow}

Analysis of the effect of filtering on rainfall measurements in Sect. 3.1 demonstrated that the filter algorithm works well in general. The resulting artefacts for light precipitation are influenced by noise status and rainfall characteristics (e.g. amount and intensity). However, the effect of filtering on snowfall measurements has not been verified.

Here we demonstrate the observed precipitation features (frequency) of rainfall and snowfall at the windy sites BC, WNC, TVC, and MC in Fig. 7. The very light rainfall class $\left(\leq 0.2 \mathrm{~mm} 30 \mathrm{~min}^{-1}\right.$ ) occurs most frequently, 36 to $56 \%$ of the time, with a mean of $43 \%$ at the former three sites. The corresponding snowfall frequency ranges from 34 to $67 \%$ with a mean of $62 \%$, whereas it is the other way round at MC. Considering that wind speed is higher in the cold period than warm period, more light solid precipitation is prone to be obscured by diurnally fluctuating noise in the cold period, resulting in more filtering artefacts. In addition, since very high wind speed $\left(>10 \mathrm{~m} \mathrm{~s}^{-1}\right)$ events mainly concentrate in the cold period - for example, at WNC and TVC - bias correction with low catch efficiency will amplify the artefacts of filtering on light solid precipitation. Therefore, the effect of filtering on snowfall precipitation needs more attention in future. 

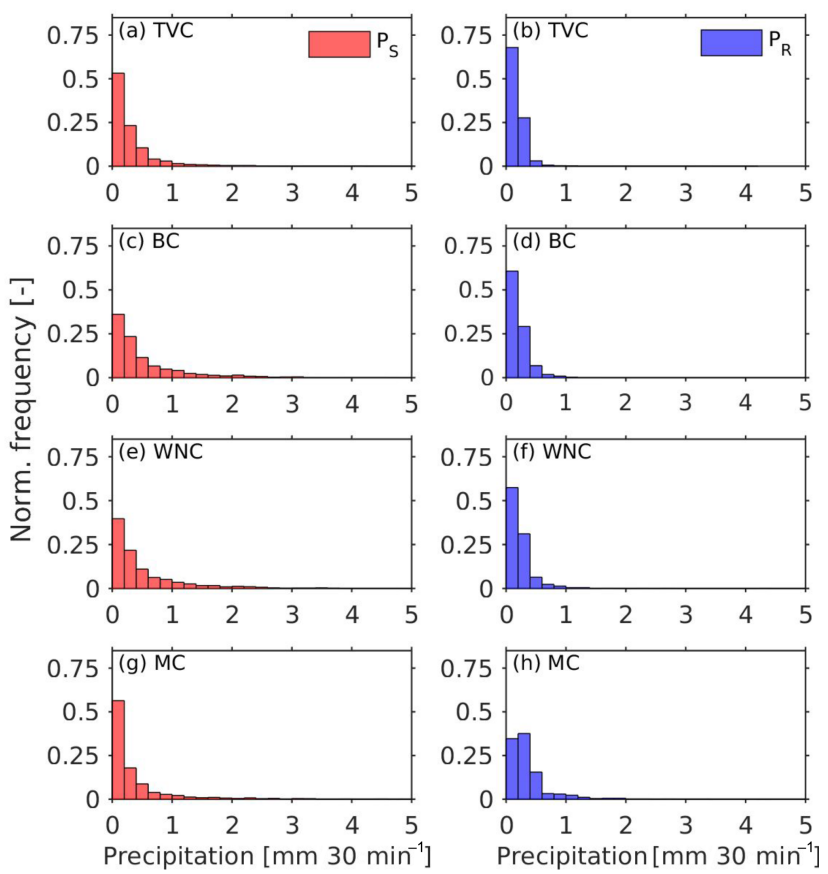

Figure 7. Histogram of $30 \mathrm{~min}$ rainfall ( $P_{\mathrm{R}}$ : left column panels) and snow ( $P_{\mathrm{S}}$ : right column panels) at four windy sites (TVC, BC, $\mathrm{WNC}$, and $\mathrm{MC}$ ). For better visualization for light precipitation, low frequencies of the precipitation over $5 \mathrm{~mm} 30 \mathrm{~min}^{-1}$ were cut out.

\subsection{Limitation of the wind speed-undercatch relationship}

The results of this study may be limited by uncertainties and limitations in Eq. (1), which empirically relates the CE for solid precipitation to wind speed. One limitation is related to the observation interval of the DFIR with a manual gauge. Limited by the half-day or daily interval of manual observations of the DFIR at the Brats Lake experimental site in Saskatchewan, an adjusted double-fenced Geonor gauge (Geonor-DF) hourly catch is indirectly referenced for the Geonor-SA catch. Recent data from DFIR with a Geonor gauge (Geonor-DFIR) are available from Brats Lake, and they are useful to improve the catch-wind relationship for various automatic precipitation gauges. For example, the correction function for the Geonor-DFIR vs. the Geonor-SA has been derived, using the intercomparison data from Norway (Wolff et al., 2015). Its applicability to different regions and climatic conditions may need testing and validation. We will consider testing various bias correction methods in future analysis.

\subsection{Effect of blowing snow and high winds}

Blowing snow fluxes collected by precipitation gauges are called false precipitation measurements (Golubev, 1989). It is a challenge to quantify the effects of blowing snow on
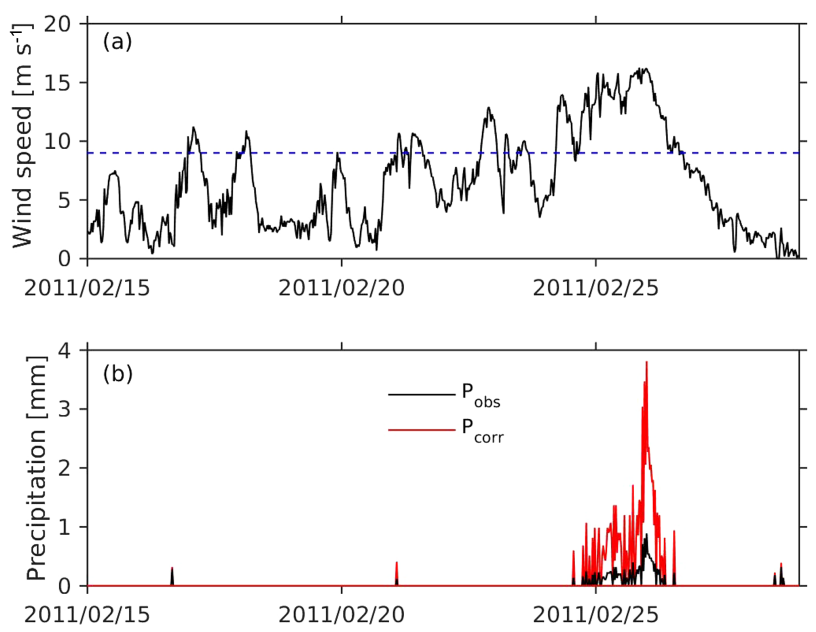

Figure 8. Example of a plausible blowing snow event at TVC site. (a) Wind speed (dashed line: upper wind speed threshold for bias correction), and (b) observed and bias-corrected snowfall over the period from 15 February to 1 March 2011.

snowfall measurements because of a lack of necessary information. The magnitude of false precipitation is proportional to the intensity of the blowing snow and its duration. Based on field observations at a windy alpine location in the Colorado Front Range, Bardsley and Williams (1997) reported that blowing snow events often occur after storms with high wind speeds, over $20 \mathrm{~m} \mathrm{~s}^{-1}$, and may introduce $50 \%$ overcatch over a winter season. Yang and Ohata (2001) found an association between higher wind speeds and higher snow measurement by the Tretyakov gauges at the windy and cold Tiksi and Dekson stations on the northern Siberian coast, perhaps resulting from snow blowing into the gauges. However, the quantity of overcatch by blowing snow might be overestimated due to the small mass concentrations of blowing snow at gauge height and the small terminal fall velocities (Pomeroy and Male, 1992). Blowing snow events were not identified in the data we used for this study. Figure 8 shows an example of a plausible blowing snow event in 2011 at TVC. The continuously high wind speed events $\left(W_{\mathrm{s}}>9 \mathrm{~m} \mathrm{~s}^{-1}\right)$ had lasted for more than 1 day around 26 February, and the corresponding bias adjustments, at the upper wind speed threshold, were at the adjustment maximum of $381 \%$. If the measurement included "false precipitation" during blowing snow, the use of a bias correction would clearly magnify the forged precipitation. Unfortunately, information on blowing snow duration and intensity, critical to determining the blowing snow flux and its impact on gauge observations in cold regions, is mostly unavailable (Sugiura et al., 2006, 2009). Because of the uncertainty in gauge performance during high-wind conditions, it is difficult to assess the impact of blowing snow. More data collection using automated instruments in the cold regions and analyses of 
snowfall in higher wind conditions, including blowing snow events, are necessary.

\section{Conclusions}

This study applied a consistent filtering procedure for subhourly precipitation measurements from Geonor-SA gauges at seven experimental sites across different ecoclimatic regions in western Canada. It quantified the wind-induced biases in precipitation records over the period of 2006-2015 and documented variations and impacts of observation errors on precipitation patterns among the sites. The main conclusions are summarized as follows.

Two major types of noise are found in Geonor gauge measurements: short-term fluctuations with occasional spurious and irregular drops, and prolonged periods of decline. The former is related to temperature and wind speed changes, and the latter is caused by evaporation losses. The application of the applied filtering procedure effectively removes these noises, as evidenced in the good agreement between rainfall measurements by the Geonor and TBRG gauges. However, the filter also introduces a few artefacts, removing some actual events and creating a few spurious ones, with an annual offset of rainfall less than $20 \mathrm{~mm} \mathrm{yr}^{-1}$.

Depending on the shielding of surrounding vegetation, the wind corrections for snow undercatch vary significantly. For the sites WCB, WCF, and BERMS with shielding by forest or brush, the bias corrections are small. In contrast, corrections vary greatly among the open sites TVC, BC, WNC, and $\mathrm{MC}$, depending on regional climate factors such as air temperature, wind speed, and snowfall percentage. On a yearly basis, the bias corrections increase total precipitation by 8 to $20 \mathrm{~mm}$, or $3-4 \%$, at the sites with vegetation shielding and 60 to $384 \mathrm{~mm}$, or $15-34 \%$, at the open sites. Bias corrections also alter the seasonal patterns of precipitation at the windy open sites where a large portion of precipitation falls as snow (WNC and TVC).

The effect of bias corrections on precipitation regime shows distinct regional features. For the rainfall-dominated climatic regime in the Prairie region (e.g. BC and WNC), bias corrections only slightly modify the seasonal patterns. For the Arctic region (e.g. TVC), significant changes in precipitation regime occur after bias corrections due to higher gauge undercatch of snowfall in windy and cold climate conditions. For the Rocky Mountain Front Range (e.g. MC), the highest change among the sites is caused by high snow percentage and high wind speeds.

\section{Data availability}

The meteorological data set of the CCRN sites is partially available through the CCRN web page at http:// giws.usask.ca/meta/. The latest unpublished data set is available by contacting each investigator: (1) Trail Valley
Creek (TVC): Philip Marsh (philip.marsh@outlook.com); (2) Wolf Creek/buckbrush (WCB) and Wolf Creek/forest (WCF): Richard Janowicz (Richard.Janowicz@gov.yk.ca); (3) BERMS/old jack pine (BERMS): Andrew Black (andrew.black@ubc.ca); (4) Brightwater Creek/Kenaston (BC): Warren Helgason (warren.helgason@usask.ca); (5) West Nose Creek/Woolliams Farm (WNC): Masaki Hayashi (hayashi@ucalgary.ca); and (6) Marmot Creek/Fisera Ridge (MC): May Guan (may.x.j.guan@usask.ca).

Acknowledgements. The following organizations provided data sets or funded field programmes for data collection: the Natural Sciences and Engineering Research Council (NSERC) Changing Cold Regions Network; Environment Canada, Yukon Environment, Alberta Agriculture and Forestry and CFCAS IP3 Network; Alberta Environment, NSERC Discovery Grant, Canada-Alberta Water Supply Expansion Program; Royal Bank of Canada, Environment Canada Science Horizons Program; and Canadian Foundation for Climate and Atmospheric Science (DRI Network). We appreciate Bruce Johnson for supplying field photos of the gauges and Philip Harder's assistance for precipitation phase determination. The authors gratefully acknowledge the support from the Global Institute of Water Security, University of Saskatchewan.

Edited by: M. Wolff

Reviewed by: two anonymous referees

\section{References}

Adam, J. and Lettenmaier, D. P.: Adjustment of global gridded precipitation for systematic bias, J. Geophys. Res., 108, 4257, doi:10.1029/2002JD002499, 2003.

Baker, B., Buckner, R., Collins, W., and Phillips, M.: Calculation of USCRN Precipitation from Geonor Weighing Precipitation Gauge, NOAA Technical Note NCDC No. USCRN-05-1, NOAA, US Department of Commerce, National Oceanic and Atmospheric Administration, 2005.

Bardsley, T. and Williams, M. W.: Overcollection of solid precipitation by a standard precipitation gauge, Niwot Ridge, Colorado, in: Proc. Western Snow Conf., Banff, AB, Canada, 354-362, 1997.

Barr, A., Black, T. A., and McCaughey, H.: Climatic and phenological controls of the carbon and energy balances of three contrasting Boreal Forest ecosystems in western Canada, in: Phenology of Ecosystem Processes, edited by: Noormets, A., Springer, New York, NY, 2009.

DeBeer, C. M., Wheater, H. S., Carey, S. K., and Chun, K. P.: Recent climatic, cryospheric, and hydrological changes over the interior of western Canada: a review and synthesis, Hydrol. Earth Syst. Sci., 20, 1573-1598, doi:10.5194/hess-20-1573-2016, 2016.

Devine, K. A. and Mekis, É.: Field accuracy of Canadian rain measurements, Atmos.-Ocean., 46, 213-227, doi:10.3137/ao.460202, 2008.

Duchon, C. E.: Using vibrating-wire technology for precipitation measurements, in: Precipitation: Advances in Measurement, Estimation and Prediction, edited by: Michaelides, S., SpringerVerlag, Berlin, 33-58, 2008. 
Emerson, D. G. and Macek-Rowland, K. M.: Solid precipitation (snowfall) measurement intercomparison, Bismarck, North Dakota, US Geological Survey Fact Sheet 90-124, US Geological Survey, US Geological Survey, Department of the Interior, p. 2, 1990

Fang, X., Pomeroy, J. W., Ellis, C. R., MacDonald, M. K., DeBeer, C. M., and Brown, T.: Multi-variable evaluation of hydrological model predictions for a headwater basin in the Canadian Rocky Mountains, Hydrol. Earth Syst. Sci., 17, 1635-1659, doi:10.5194/hess-17-1635-2013, 2013.

Fortin, V., Therrien, C., and Anctil, F.: Correcting wind-induced bias in solid precipitation measurements in case of limited and uncertain data, Hydrol. Process., 22, 3393-3402, 2008.

GEONOR: GEONOR T-200B Precipitation Gauge User Manual, Campbell Scientific (Canada) Corp., Edmonton, 2016.

Golubev, V. S.: Assessment of accuracy characteristics of the reference precipitation gauge with a double-fence shelter, in: Final report of the Fourth Session of the International Organizing Committee for the WMO solid precipitation measurement intercomparison, WMO, St. Moritz, Switzerland, 34-41, 1989.

Goodison, B. E., Louie, P. Y. T., and Yang, D.: WMO solid precipitation measurement intercomparison, WMO/TD 872, World Meteorol. Org., Geneva, 212 pp., 1998.

Harder, P. and Pomeroy, J.: Estimating precipitation phase using a psychrometric energy balance method, Hydrol. Process., 27, 1901-1914, doi:10.1002/hyp.v27.13, 2013.

Harder, P., Pomeroy, J. W., and Westbrook, C. J.: Hydrological resilience of a Canadian Rockies headwaters basin subject to changing climate, extreme weather, and forest management, Hydrol. Process., 29, 3905-3924, 2015.

Hayashi, M. and Farrow, C. R.: Watershed-scale response of groundwater recharge to inter-annual and inter-decadal variability in precipitation, Hydrogeol. J., 22, 1825-1839, 2014.

Janowicz, J. R., Hedstrom, N., Pomeroy, J. W., Granger, R., and Carey, S. K.: Wolf Creek Research Basin water balance studies, in: Northern Research Basins Water Balance, IAHS Publ. No. 290, edited by: Kane, D. L. and Yang, D., IAHS Press, Wallingford, UK, 195-204, 2004.

Lamb, H. H. and Swenson, J.: Measurement errors using a Geonor weighing gauge with a Campbell Scientific Datalogger, in: Paper P2.5, Proceedings 16th Conference on Climate Variability and Change, American Meteorological Society, San Diego, CA, 2005

List, R. J.: Smithsonian Meteorological Tables, revised 6th Edn., Smithsonian Institution Press, Washington, D.C., 527 pp., 1951.

Marsh, P., Onclin, C., and Russell, M.: A multi-year hydrological data set for two research basins in the Mackenzie Delta region, NW Canada, in: Northern Research Basins water balance Proceedings of a workshop, 15-19 March 2004, Victoria, Canada, 205-212, 2004.

Mohammed, G. A., Hayashi, M., Farrow, C. R., and Takano, Y.: Improved representation of frozen soil processes in the Versatile Soil Moisture Budget model, Can. J. Soil Sci., 93, 511-531, 2013.

Pipes, A. and Quick, M.: UBC Watershed Model Users Guide, Department of Civil Engineering, University of British Columbia, 1977.

Pomeroy, J. W. and Male, D. H.: Steady-state suspension of snow, J. Hydrol., 136, 275-301, 1992.
Pomeroy, J. W., Gray, D. M., and Landine, P. G.: The Prairie Blowing Snow Model: characteristics, validation, operation, J. Hydrol., 144, 165-192, 1993.

Pomeroy, J. W., Marsh, P., and Gray, D. M.: Application of a distributed blowing snow model to the Arctic, Hydrol. Process., 11, 1451-1464, 1997.

Pomeroy, J. W., Gray, D. M., Hedstrom, N. R., and Janowicz, J. R.: Physically based estimation of seasonal snow accumulation in the Boreal Forest, in: Proceedings of the 59th Eastern Snow Conference, Stowe, VT, 93-108, 2002.

Pomeroy, J. W., Bewley, D., Essery, R. L. H., Hedstrom, N. R., Link, T. E., Granger, R. J., Sicart, J. E., Ellis, C. R., and Janowicz, J. R.: Shrub tundra snowmelt, Hydrol. Process., 20, 923-941, 2006.

Pomeroy, J. W., Fang, X., and Ellis, C.: Sensitivity of snowmelt hydrology in Marmot Creek, Alberta, to forest cover disturbance, Hydrol. Process., 26, 1891-1904, 2012.

Rasouli, K., Pomeroy, J. W., Janowicz, J. R., Carey, S. K., and Williams, T. J.: Hydrological sensitivity of a northern mountain basin to climate change, Hydrol. Process., 28, 4191-4208, doi:10.1002/hyp.10244, 2014

Raupach, M. R., Finnigan, J. J., and Brunet, Y.: Coherent eddies and turbulence in vegetation canopies: the mixing-layer analogy, Bound.-Layer Meteorol., 78, 351-382, 1996.

Rogers, R. R. and Yau, M. K.: A Short Course in Cloud Physics, 3rd Edn., Butterworth-Heinemann, Burlington, MA, 304 pp. 1989.

Smith, C. D.: Correcting the wind bias in snowfall measurements made with a Geonor T-200B precipitation gauge and Alter wind shield, in: Proceedings of the 14th SMOI, San Antonio, 2007.

Storr, D.: Precipitation variations in a small forested watershed, in: Proceedings of the Annual Western Snow Conference, Boise, Idaho, 11-17, 1967.

Sugiura, K., Ohata, T., and Yang, D.: Catch characteristics of precipitation in high-latitude regions with high winds, J. Hydrometeorol., 7, 984-994, 2006.

Sugiura, K., Ohata, T., and Yang, D.: Application of a snow particle counter to solid precipitation measurements under Arctic conditions, Cold Reg. Sci. Technol., 58, 77-83, 2009.

Thorpe, A. D. and Mason, B. J.: The evaporation of ice spheres and ice crystals, Br. J. Appl. Phys., 17, 541-548, 1966.

Wahl, H. E., Fraser, D. B., Flarvey, R. C., and Maxwell, J. B.: Climate of Yukon, Climatological Studies Number 40, Environment Canada, Atmospheric Environment Service, Ottawa, Canada, 1987.

Wang, Y. and Cionco, R.: Wind profiles in gentle terrains and vegetative canopies for a three-dimensional wind field (3DWF) model, Report No. ARL-TR-4178, US Army Research Laboratory Computational and Information Sciences Directorate, Adelphi, 2007.

WMO: Commission for instrument and methods of observation, Final Report of the Fifth Session (CIMO-V) abridged, WMONo. 252.RP.82, World Meteorological Organization, Geneva, 1969.

Wolff, M. A., Isaksen, K., Petersen-Øverleir, A., Ødemark, K., Reitan, T., and Brækkan, R.: Derivation of a new continuous adjustment function for correcting wind-induced loss of solid precipitation: results of a Norwegian field study, Hydrol. Earth Syst. Sci., 19, 951-967, doi:10.5194/hess-19-951-2015, 2015. 
Yang, D. and Ohata, T.: A bias corrected Siberian regional precipitation climatology, J. Hydrometeorol., 2, 122-139, 2001.

Yang, D. and Simonenko, A.: Comparison of winter precipitation measurements by six Tretyakov gauges at the Valdai experimental site, Atmos.-Ocean, 52, 39-53, doi:10.1080/07055900.2013.865156, 2014.

Yang, D., Goodison, B. E., Benson, C. S., and Ishida, S.: Adjustment of daily precipitation at 10 climate stations in Alaska: Application of WMO Intercomparison results, Water Resour. Res., 34, 241-256, 1998.
Yang, D., Goodison, B. E., Metcalf, J. R. Louie, P. Y., Leavesley, G. H., Emerson, D. G., Hanson, C. L., Golubev, V. S., Esko, E., Gunther, T., Pangburn, T., Kang, E., and Milkovic, J.: Quantification of precipitation measurement discontinuity induced by wind shields on national gauges, Water Resour. Res., 35, 491508, 1999.

Yang, D., Kane, D., Zhang, Z., Legates, D., and Goodison, B.: Bias corrections of long-term (1973-2004) daily precipitation data over the northern regions, Geophys. Res. Lett., 32, L19501, doi:10.1029/2005GL024057, 2005. 